OPEN ACCESS

Edited by:

Luc Pieters,

University of Antwerp, Belgium

Reviewed by:

Jose-Luis Rios,

Universitat de València, Spain

Cassandra L. Quave,

Emory University School of Medicine

United States

${ }^{*}$ Correspondence:

Andy Wai Kan Yeung ndyeung@hku.hk

Michael Heinrich

m.heinrich@ucl.ac.uk

Atanas G. Atanasov

a.atanasov.mailbox@gmail.com

Specialty section: This article was submitted to

Ethnopharmacology,

a section of the journal

Frontiers in Pharmacology

Received: 05 January 2018 Accepted: 27 February 2018

Published: 15 March 2018

Citation:

Yeung AWK, Heinrich $M$ and Atanasov AG (2018) Ethnopharmacology - A Bibliometric Analysis of a Field of Research Meandering Between Medicine and

Food Science?

Front. Pharmacol. 9:215 doi: 10.3389/fphar.2018.00215

\section{Ethnopharmacology-A Bibliometric Analysis of a Field of Research Meandering Between Medicine and Food Science?}

\author{
Andy Wai Kan Yeung ${ }^{1 *}$, Michael Heinrich ${ }^{2 *}$ and Atanas G. Atanasov ${ }^{3,4 *}$ \\ 1 Oral and Maxillofacial Radiology, Applied Oral Sciences, Faculty of Dentistry, The University of Hong Kong, Hong Kong, \\ Hong Kong, ${ }^{2}$ Research Group "Pharmacognosy and Phytotherapy", UCL School of Pharmacy, London, United Kingdom, \\ ${ }^{3}$ Institute of Genetics and Animal Breeding, Polish Academy of Sciences, Magdalenka, Poland, ${ }^{4}$ Department of \\ Pharmacognosy, University of Vienna, Vienna, Austria
}

Background: The research into bioactive natural products of medicinal plants has a long tradition, but ethnopharmacology as a well-defined field of research has a relatively short history, only dating back 50 years.

Aims: With the fast development of this field and its global importance especially in the fast developing economies of Asia it is timely to assess the most influential articles (as measured by citations) and to identify important drivers and research trends in this field.

Methods: Scopus was searched to identify relevant articles which were assessed by all three authors. The 100 most cited articles were identified and analyzed. Bibliometric software (VOSviewer) was utilized to supplement the analysis and to generate a term map that visualized the citation patterns of the 100 articles containing different terms.

Results: Forty-four of the 100 articles are reviews. On average, each of the 100 articles had 632 citations and since publication was cited 43 times annually. The four core journals were Journal of Ethnopharmacology $(n=17)$, Food Chemistry $(n=7)$, Life Sciences $(n=5)$, and Journal of Agricultural and Food Chemistry $(n=4)$. Anti-oxidant effects appeared to be a recurring and highly cited topic, whereas the links into drug discovery and neuropharmacology seemed to be less strong. Numerous medicinal plants and functional foods were the foci of research, and the foci shifted when comparing pre-2000 and post-2000 publications (with the later involving a broader spectrum of plants and foods and a wider range of biological effects). Contributions largely came from Asia, and also from the Americas, Africa, and Oceania, besides Europe.

Conclusion: We have identified and analyzed the 100 most-cited articles in ethnopharmacology. Within 50 years the field has gained a profile and while conventionally often linked to "traditional knowledge," drug discovery and some areas of pharmacology, this analysis highlights its emerging importance in the context of disease prevention (food science), but also the development of research driven by the needs and interests of the fast developing economies most notably of Asia.

Keywords: bibliometrics, ethnopharmacology, ethnobotany, ethnomedicine, medicinal plant, folk medicine, traditional medicine 


\section{The top papers in Ethnopharmacology}
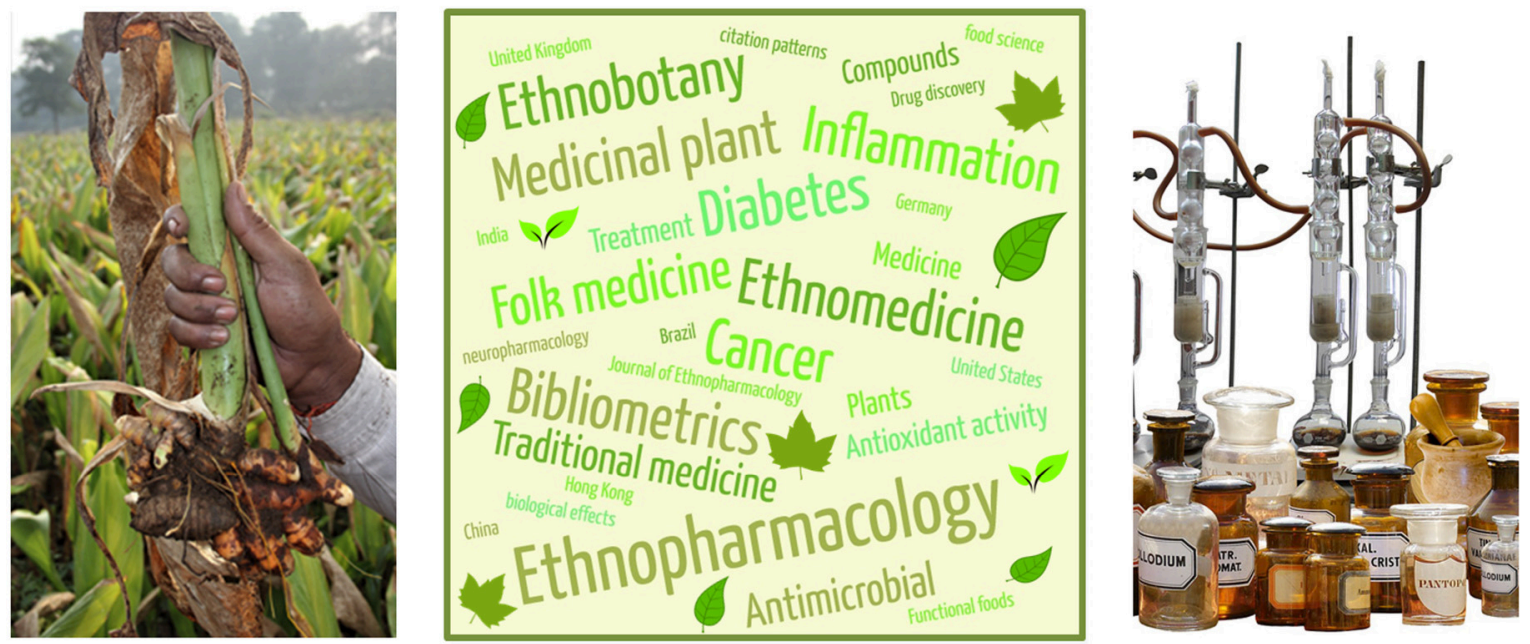

GRAPHICAL ABSTRACT:The top papers in ethnopharmacology display a crossover of medical and food science.

\section{INTRODUCTION}

Historically, there are abundant and diversified studies reporting on the biological, pharmacological, and medical uses of plants, fungi, and other organisms within a local or traditional context (Heinrich and Jäger, 2015). Many pharmaceutical agents commonly used today originate from medicinal plants, such as aspirin, morphine, pilocarpine, and quinine (Gilani, 2005), and more recently galanthamine, peplin, and Crofelmer (from Croton lechleri Müll.Arg.; Heinrich, 2013). Moreover, plants continue to be an important source for modern drug discovery aiming the development of new therapeutics (Atanasov et al., 2015). Instead of being dominated by driving forces from the "Western World," investigations in ethnopharmacology have next to European (Vogl et al., 2013) also strong global contributions from the Asian, African, and native American traditional medicine (Sheng-Ji, 2001; Steenkamp et al., 2004), such as those originating from China (Rozema et al., 2012), India (Booker et al., 2012), Southeast Asia, for example, Vietnam (Tran et al., 2015), and Mexico (Heinrich, 2000) and several South and Central American countries.

However, ethnopharmacology as a well-defined field of research has a relatively short history, dating back about 50 years only (Heinrich and Jäger, 2015). This offers an opportunity to make an overall assessment and identify important research trends in this field. With such a rich and diversified literature, it is worthwhile to conduct a bibliometric study that examines the top 100 most-cited articles within the research field of ethnopharmacology. Similar studies that reported the 100 mostcited articles have been published for numerous research fields in life science including emergency medicine (Tsai et al., 2006), neuroimaging (Kim et al., 2016), and neuroscience (Yeung et al., 2017a). This allows an understanding of the research trends in the last decades and the ongoing "hot topics." To the best of the authors' knowledge, no such bibliometric report has been published for ethnopharmacology.

The current study, therefore, aims to identify and analyze the 100 most-cited ethnopharmacology articles. The specific objectives of this analysis were:

(1) To understand what key research themes were relevant (as indicated by citations) in ethnopharmacology?

(2) To appreciate what we can learn from the highly cited papers in this field in the context of ethnopharmacology's wider and changing relevance within the natural sciences?

(3) To identify who and what has driven this research?

(4) To assess what we can learn from this for the future development of the field?

\section{MATERIALS AND METHODS}

\section{Data Sources}

Scopus was chosen as the source of data since it has a broader coverage on pharmacology journals compared to Web of Science (Gorraiz and Schloegl, 2008). It is a webbased, multidisciplinary database hosted by Elsevier, and it provides bibliometric data of peer-reviewed articles published in the life, social, physical, and health sciences. In November 2017, we searched Scopus to identify articles with the following string: TITLE-ABS-KEY (ethnopharmacology OR ethnopharmacological OR ethnobotany OR ethnobotanical OR ethnomedicine OR ethnomedical OR "medicinal plant" OR "folk medicine" OR "traditional medicine”). This string searched for 
articles that contain any of these terms or phrases in their title, abstract, or keywords.

The articles were sorted by citation count in descending order. All authors (AWKY, MH, and AGA) screened the titles and abstracts of the articles to exclude those irrelevant to ethnopharmacology in order to finally include the 100 most cited articles. In the current study, we considered as ethnopharmacology papers those focused on traditional medical use or biological and pharmacological activities of plants, fungi, and other organisms used locally or traditionally as a medicine or to improve health. The definition also includes studies aimed to either improving local healthcare through developing products based on such knowledge or studies in the context of drug discovery/development from natural sources which were based on biological resources with a clear and well-defined local or traditional use. We excluded papers which simply contained some of the string keywords but the major focus of the article was not related to ethnopharmacology. These considerations are in line with the definition of ethnopharmacology adopted by the Journal of Ethnopharmacology ${ }^{1}$, Frontiers in Pharmacology (section Ethnopharmacology) ${ }^{2}$ and the ConSEFS advisory group (Heinrich et al., 2018).

No additional restrictions were placed on the type of research model (in vivo/in vitro), article type (e.g., research article, review, editorial, letter, etc.), or publication language.

\section{Data Extraction}

The 100 most-cited articles were evaluated and the following information extracted: (1) publication year; (2) journal title; (3) journal impact factor at the time of publication; (4) SCImago Journal Rank at the time of publication (SJR indicator, which weighs citations by the importance or prestige of the citing journals); (5) total citation count; (6) adjusted citation count (i.e., citation count per year since publication); (7) field-weighted citation impact $(\mathrm{FWCI})^{3} ;(8)$ authorship; and (9) article type. In addition, the scopes of the involved journals were classified into nine categories: clinical, ethnopharmacology, and medicinal plant research, food research (chemistry etc.), multidisciplinary journals, microbiology and biotechnology, pharmacology and pharmacy, phytochemistry with a link to traditional uses, plant science, and social sciences.

Bradford's law of scattering was applied to the 100 mostcited articles to investigate if a few core journals accounted for publishing one-third of these articles (Vickery, 1948; Yeung et al., 2017c). Based on Bradford's law, three groups of journals should contribute to the publication of the 100 articles when it is equally divided into three portions, whereas the number of journals within the groups should be in the ratio of $1: n: \mathrm{n}^{2}$. For instance, if one journal publishes 33 articles and the next 33 articles are

\footnotetext{
${ }^{1}$ https://www.journals.elsevier.com/journal-of-ethnopharmacology/

${ }^{2}$ https://www.frontiersin.org/journals/pharmacology/sections/ ethnopharmacology\#about

${ }^{3} \mathrm{FWCI}$ shows how well cited an article is as compared to similar ones. It considers the publication year, article type and disciplines associated with its source. It is the ratio of the total citations actually received by the article to the total citations that would be expected based on the average of the subject field. For instance, a FWCI of 1.50 means the article was cited $50 \%$ more times than expected.
}

published by four journals, the remaining 33 articles should be published by 16 journals (1:4:16).

\section{Statistical Analysis}

We tested if years since publication would influence the number of citations of the articles. It was tested by Pearson's correlation test. Test result with $p<0.05$ was considered statistically significant.

\section{Term Map}

Words in the titles and abstracts of these 100 articles were parsed, analyzed and visualized by VOSviewer (Van Eck and Waltman, 2009), a bibliometric software that visualizes results as bubble maps. Each bubble represented a term or phrase. Irrelevant terms were manually screened and removed (Heersmink et al., 2011; Yeung et al., 2017c). The bubble size indicated its frequency of occurrence. The bubble color indicated the averaged citation counts received by articles containing the term or phrase. A line connects two bubbles if they co-occurred in any of the 100 articles. If two terms co-occurred more frequently, the two bubbles will be in closer proximity. The term map visualizes terms that appeared in at least five of the 100 articles.

\section{RESULTS AND DISCUSSION}

The 100 most-cited ethnopharmacology articles were mainly original articles $(n=51)$ and reviews $(n=44)$, with a few conference papers $(n=3)$ and short surveys $(n=2)$. Since such a bibliometric assessment is not available for general pharmacology, no direct comparison is possible. However, one can compare the size of the respective fields. A search in Scopus replacing our pre-defined search terms with different ones has revealed that there are 181,207 papers tagged as "pharmacology," 4,998 papers as "neuropharmacology," 3,450 papers as "ethnopharmacology," and 39,848 papers as "traditional medicine/ethnopharmacology."

The number of citations received by these 100 articles ranged from 353 to 5,253 (mean \pm SD: $631.7 \pm 560.0$, cumulative total citations $=63,166$; Table 1 ). The adjusted citation count (i.e., citation count per year since publication) ranged from 10.8 to 276.5 (mean \pm SD: $43.3 \pm 31.2$, Table 1). Regardless of total citation count or adjusted citation count, Eisenberg et al. (1998) published the top-ranked article, a national survey reporting trends in alternative medicines use in the United States.

The 100 articles were published in 59 journals with impact factors ranging from 0 to 29.8 (mean \pm SD: $2.7 \pm 3.8$ ). Half of the 100 articles were published either in a journal dedicated to ethnopharmacology and medicinal plant research $(n=28)$ or a clinical journal ( $n=19$; Table 2). Only one article was published in a social sciences journal. Four core journals published 33 articles; 21 and 34 journals, respectively, published the next 33 and the last 33 articles (4:21:34). This indicated that the distribution of publications did not fulfill Bradford's law. The four core journals were Journal of Ethnopharmacology $(n=17)$, Food Chemistry $(n=7)$, Life Sciences $(n=5)$, and Journal of Agricultural and Food Chemistry $(n=4)$. 


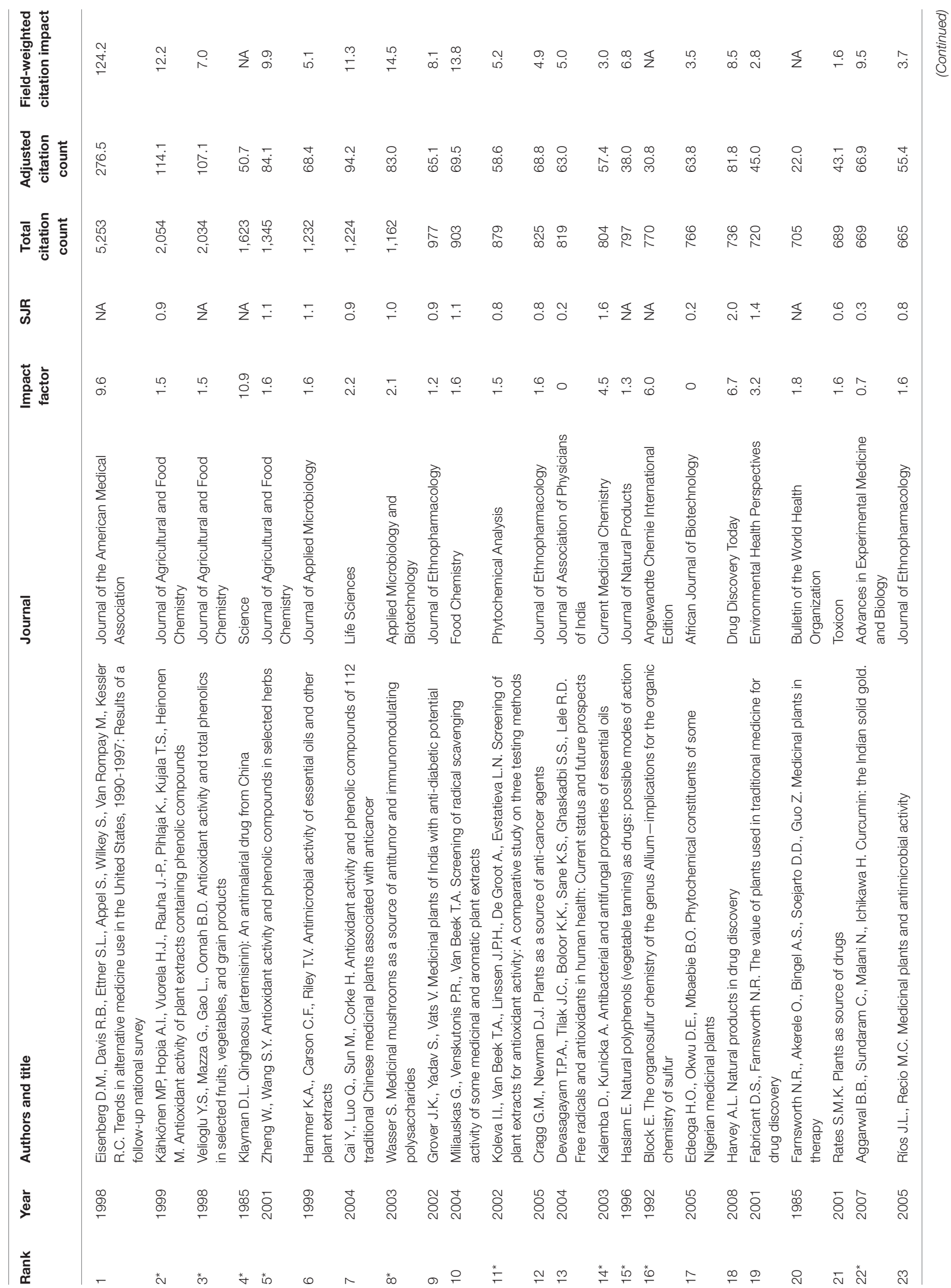




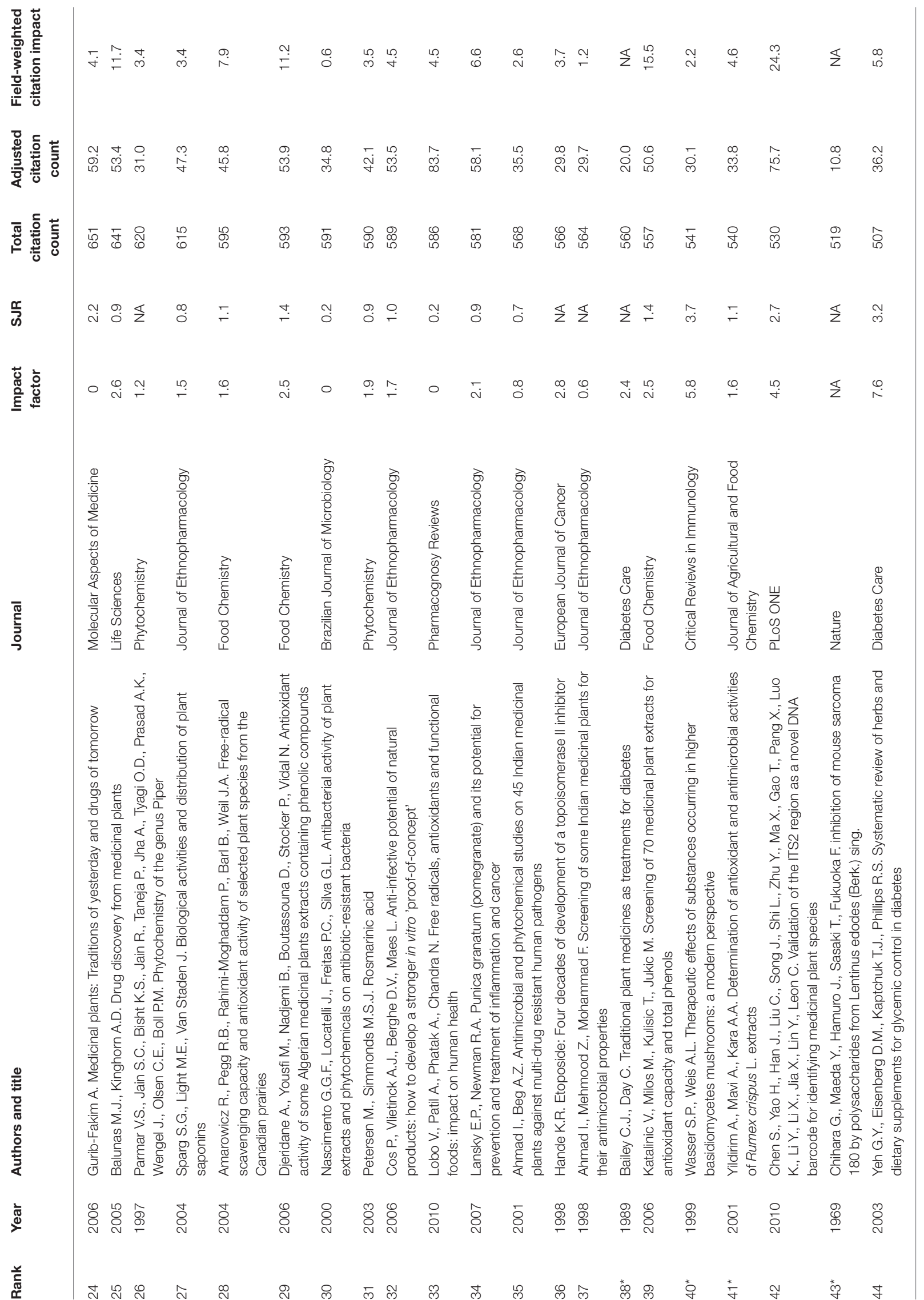




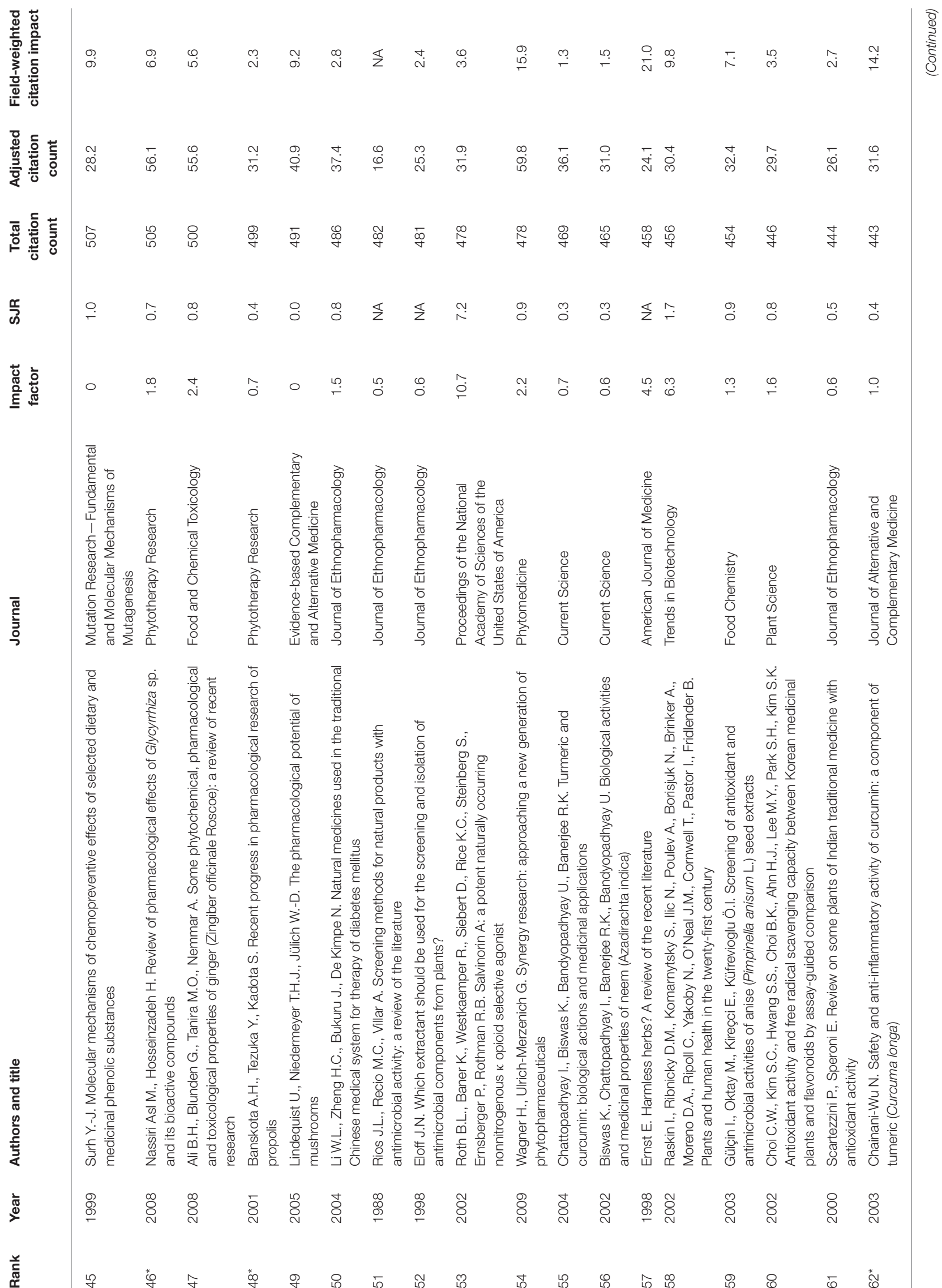




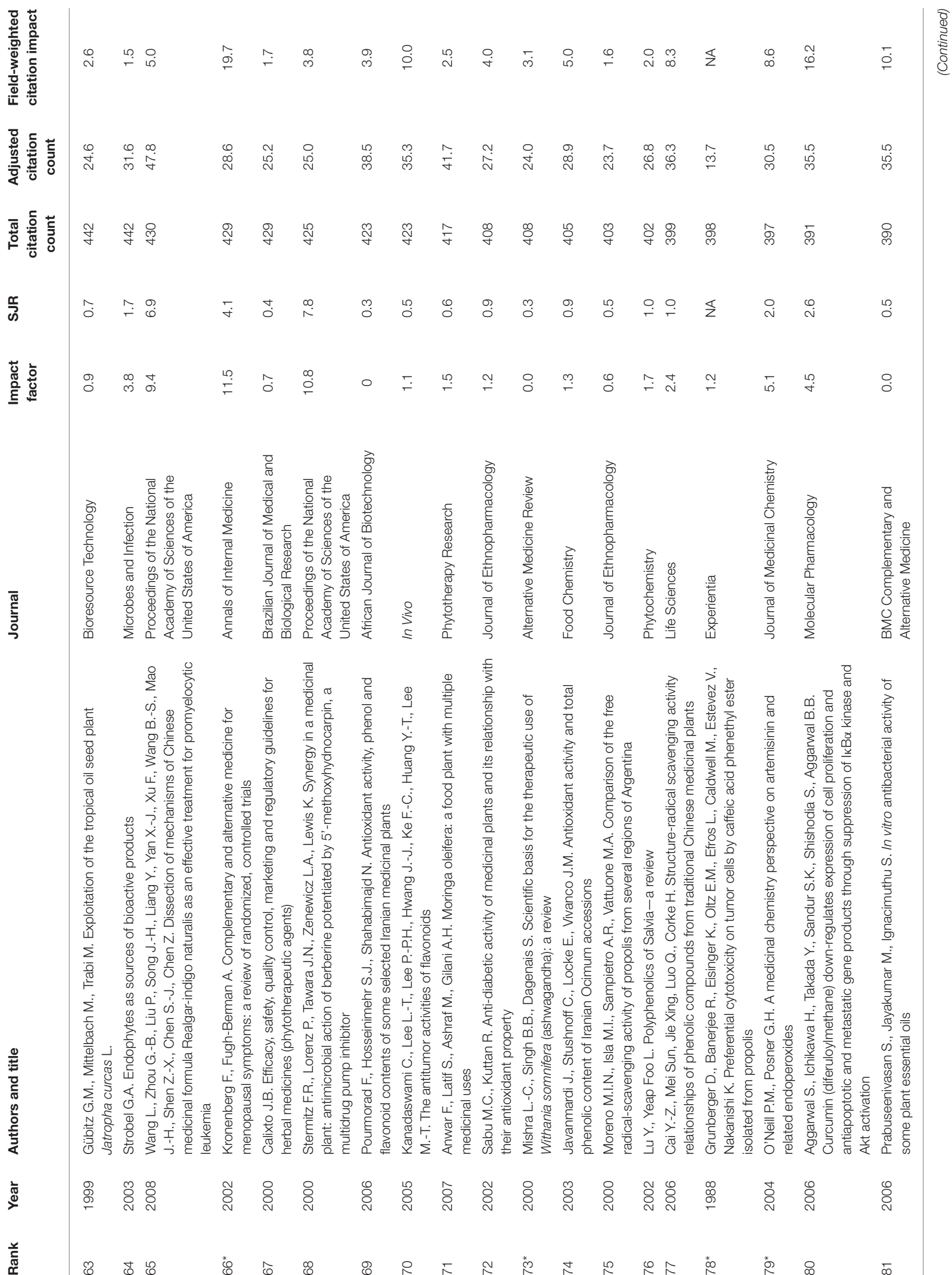




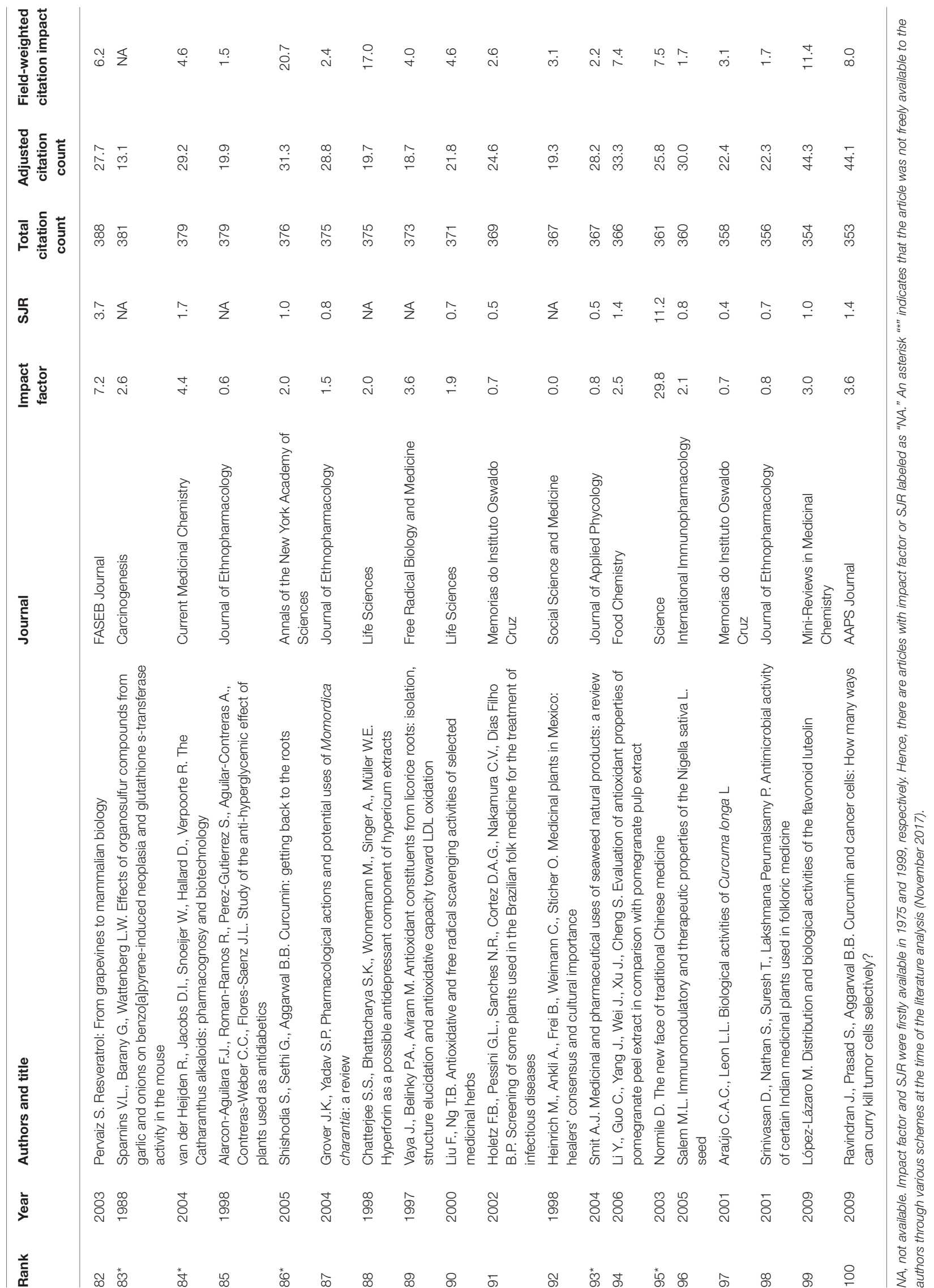


TABLE 2 | Journals in which the 100 most-cited ethnopharmacology articles were published.

\begin{tabular}{|c|c|c|c|c|}
\hline Journal & Publication count & Citation count & Citation per article & Topic \\
\hline Food Chemistry & 7 & 3,873 & 553 & 1 \\
\hline Journal of Agricultural Food Chemistry & 4 & 5,973 & 1,493 & 1 \\
\hline Phytochemistry & 3 & 1,612 & 537 & 3 \\
\hline Science & 2 & 1,984 & 992 & 6 \\
\hline African Journal of Biotechnology & 2 & 1,189 & 595 & 7 \\
\hline Current Medicinal Chemistry & 2 & 1,183 & 592 & 3 \\
\hline Diabetes Care & 2 & 1,067 & 534 & 5 \\
\hline Current Science & 2 & 934 & 467 & 6 \\
\hline Applied Microbiology and Biotechnology & 1 & 1,162 & & 7 \\
\hline Phytochemical Analysis & 1 & 879 & & 3 \\
\hline Journal of Association of Physicians of India & 1 & 819 & & 5 \\
\hline Journal of Natural Products & 1 & 797 & & 3 \\
\hline Angewandte Chemie International Edition & 1 & 770 & & 3 \\
\hline Drug Discovery Today & 1 & 736 & & 3 \\
\hline Environmental Health Perspectives & 1 & 720 & & 4 \\
\hline Bulletin of the World Health Organization & 1 & 705 & & 5 \\
\hline Toxicon & 1 & 689 & & 4 \\
\hline Advances in Experimental Medicine and Biology & 1 & 669 & & 4 \\
\hline Molecular Aspects of Medicine & 1 & 651 & & 4 \\
\hline Food and Chemical Toxicology & 1 & 500 & & 4 \\
\hline Evidence-Based Complementary and Alternative Medicine & 1 & 491 & & 2 \\
\hline Phytomedicine & 1 & 478 & & 2 \\
\hline American Journal of Medicine & 1 & 458 & & 5 \\
\hline Trends in Biotechnology & 1 & 456 & & 7 \\
\hline Plant Science & 1 & 446 & & 8 \\
\hline Journal of Alternative and Complementary Medicine & 1 & 443 & & 2 \\
\hline Bioresource Technology & 1 & 442 & & 7 \\
\hline Microbes and Infection & 1 & 442 & & 7 \\
\hline Annals of Internal Medicine & 1 & 429 & & 5 \\
\hline Brazilian Journal of Medical and Biological Research & 1 & 429 & & 5 \\
\hline In Vivo & 1 & 423 & & 5 \\
\hline Alternative Medicine Review & 1 & 408 & & 5 \\
\hline Experientia & 1 & 398 & & 5 \\
\hline Journal of Medicinal Chemistry & 1 & 397 & & 3 \\
\hline Molecular Pharmacology & 1 & 391 & & 5 \\
\hline BMC Complementary and Alternative Medicine & 1 & 390 & & 2 \\
\hline
\end{tabular}


TABLE 2 | Continued

\begin{tabular}{|c|c|c|c|c|}
\hline Journal & Publication count & Citation count & Citation per article & Topic \\
\hline FASEB Journal & 1 & 388 & & 5 \\
\hline Carcinogenesis & 1 & 381 & & 5 \\
\hline Annals of the New York Academy of Sciences & 1 & 376 & & 6 \\
\hline Free Radical Biology and Medicine & 1 & 373 & & 5 \\
\hline Journal of Applied Phycology & 1 & 367 & & 8 \\
\hline Social Science and Medicine & 1 & 367 & & 9 \\
\hline International Immunopharmacology & 1 & 360 & & 4 \\
\hline Mini-Reviews in Medicinal Chemistry & 1 & 354 & & 3 \\
\hline AAPS Journal & 1 & 353 & & 5 \\
\hline
\end{tabular}

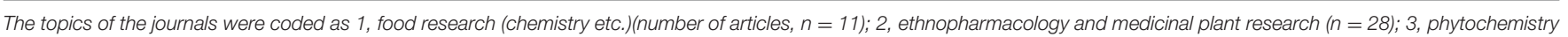

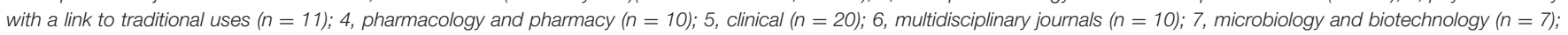
8, plant science $(n=2)$; and 9, social sciences $(n=1)$.

\section{What Key Research Themes Were Relevant (as Indicated by Citations) in Ethnopharmacology?}

There were 76 terms or phrases that appeared in five or more of the 100 articles (Figure 1). Figure 1 clearly suggested that terms or phrases related to anti-oxidant effects received much more citations per article than the average, as reflected by the red-orange-yellow-green bubbles concentrated on the lower right corner of the term map. For instance, "total phenolic content" appeared in seven articles with an average of 1,175 citations each. "Gallic acid equivalent" appeared in five articles with an average of 1,126 citations each. "Antioxidant activity" appeared in 18 articles with an average of 797 citations each. "DPPH (2,2-diphenyl-1-picrylhydrazyl)" appeared in six articles with an average of 600 citations each. Free radical scavenging activity appeared in five articles with an average of 592 citations each. Meanwhile, seven articles had the phrase "herbal medicine" with an average of 1,148 citations each. Certain terms may reflect the geographical content of the ethnopharmacology articles, such as "traditional Chinese medicine" $(n=6)$ relates to China and "Ayurveda" $(n=6)$ relates to India. The 20 terms that appeared most in the titles and abstracts of the 100 articles are listed in Table 3.

Studies with a focus on antioxidant effects, and works focusing on fruits and other food-related species and their related concepts were often highly cited. This may be linked to the fact that antioxidant tests are usually affordable and easily available (Kedare and Singh, 2011) so the majority of the labs, regardless of their budget size, could readily use them. It also reflects the size of research fields-the food sciences field is much larger than research into medicinal plants (as well as the associated industries). The food sitting close to traditional medicine makes an interesting link to the "Let food be thy medicine and medicine be thy food" concept advocated by Hippocrates. Functional foods have an enormous global market that has recently grown from US\$33 billion (Menrad, 2003) to US $\$ 168$ billion (Vicentini et al., 2016). A substantive body of research on functional food research advocates the intake of antioxidant nutrients for better well-being and health (Diplock et al., 1998). Food plants are also easily and often commercially available through the world. In other words, resource availability may be the key concept to interpret the focus for antioxidants and food plants in general. Spices are an important topic in these studies, particularly the curcumin from turmeric (Curcuma longa L.), which was mentioned in eight of the 100 articles, including in the titles of six of the 100 articles. This is not unexpected, since many spices are heavily used in the traditional medicine (Vimala et al., 1999; Aggarwal et al., 2007; Singh, 2007). While this demonstrates the importance of the topic in bibliometric terms, readers should be aware that antioxidant tests are often based on simple chemical reactions that may not translate well to demonstrate effects in real biological systems. Currently, they are not accepted as a relevant aspect of pharmacological research (see e.g., the "Rules of Five" of the Journal of Ethnopharmacology) ${ }^{4}$.

The 100 articles involved clinical or pre-clinical research on numerous diseases. Diseases often mentioned in the 100 articles included diabetes ( $n=7 ; 565$ citations each) and cancer $(n=12$; 473 citations each). The citations of these papers are mainly from the year 2004 onwards. For instance, there is a comprehensive report that reviewed the effects of various medicinal plants originating from Asia, Europe, the Middle East, and the Americas on diabetes (Bailey and Day, 1989). Similarly, there was a report on plant-derived compounds as anti-cancer agents (Cragg and Newman, 2005).

Other diseases that were mentioned in at least three of the 100 articles included Alzheimer's disease ( $n=3 ; 564$ citations each), arthritis ( $n=4 ; 478$ citations each), and rheumatism $(n=3 ; 449$ citations each). In addition, six papers mentioned gastrointestinal disease (three of them were in the abstracts while the other three were in keywords). One paper mentioned respiratory disease. Since these terms appeared in fewer than five of the 100 articles' titles or abstracts, they were not visualized in Figure 1. No paper mentioned gynecology or dermatology. Some studies show some links into traditional medicine/ethnopharmacology, but are in essence a clinical study, for example (Kronenberg and FughBerman, 2002).

\footnotetext{
$\overline{{ }^{4} \text { https://www.sciencedirect.com/science/article/pii/S0378874105008251 }}$
} 


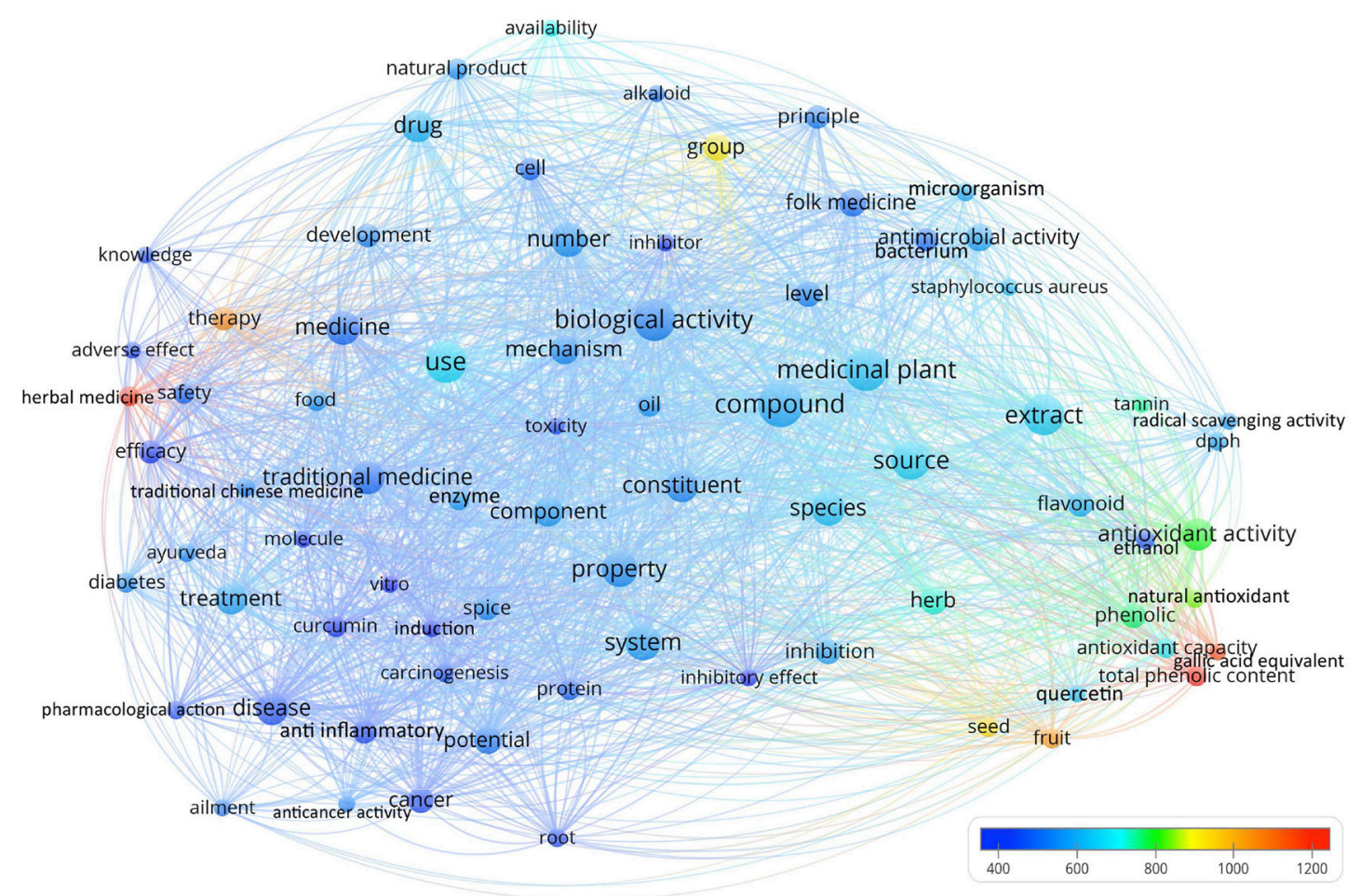

FIGURE 1 | Term map using words from titles and abstracts of the 100 most-cited ethnopharmacology articles. Words from titles and abstracts were parsed, analyzed and visualized by VOSviewer. There were 76 terms that appeared in five or more articles and hence included in the term map. Each bubble represents a term or phrase. The bubble size indicates its frequency of occurrence. The bubble color indicates the averaged citation counts received by articles containing the term or phrase. A line connects two bubbles if they co-occurred in any of the 100 articles. If two terms co-occurred more frequently, the two bubbles would be in closer proximity. Irrelevant terms were removed manually upon visual inspection of the initial map generated. Lower right corner contains numerous terms and phrases related to anti-oxidant activity and articles containing them had more citations than the average, as indicated by the red, orange, yellow, and green bubbles.

Some important metabolites and related concepts have been mentioned at least thrice in the 100 articles, including alkaloids ( $n=5$; on average 534 citations), essential oil $(n=4$; 774), flavonoids ( $n=11 ; 621)$, and tannin ( $n=5$; 752). These topics have constituted a large portion of the existing ethnopharmacology literature.

The link of the 100 ethnopharmacological papers into the context of drug discovery seemed to be marginal. Seven of the 100 papers discussed the concept of drug discovery in their titles, abstracts, or keywords. Six of the seven papers reviewed the drug discovery from Allium (garlic and onion), seaweed, medicinal plants, and natural products in general (Block, 1992; Fabricant and Farnsworth, 2001; Smit, 2004; Balunas and Kinghorn, 2005; Gurib-Fakim, 2006; Harvey, 2008). Klayman (1985) analyzed the development of artemisinin from the Chinese medicinal plant Artemisia annua L. The remaining paper demonstrated a possible major active metabolite responsible for the antidepressant effect of the extract from St. John's wort (Chatterjee et al., 1998), which happens to be the only paper dealing with St. John's wort, one of the best studied medicinal plants. Together with a paper dealing with opioid K inhibition and salvinorin (Roth et al., 2002), these two are the only ones dealing with neuropharmacology among the 100. Another interesting gap is research on Cannabis and its active metabolites tetrahydrocannabinol (THC) and cannabis (CBD). Here a large number of papers have been published, but clearly not deemed to be linked to ethnopharmacology, for example (Bisogno et al., 2001). Sustainability, access, and benefit sharing are also clearly are not major topics (as evident from Figure 1, the only term with relevance in this context seems to be "availability").

The latest papers in our top 100 list were published in 2010. Our Scopus search has identified that only two post-2010 papers had at least 300 citations, and both of them have exceeded the citation count of the last paper on our top 100 list. However, they were excluded as one focused on genomics and drug synthesis (Cragg and Newman, 2013) (582 citations) whereas the other one strictly dealt with chemistry (Kumar and Pandey, 2013; 399 citations).

The citation counts of the articles have no significant correlation with the number of years since publication $(r=0.134$, $p=0.184)$. Since the articles were generally published well before 2010, an analysis of open vs. closed access is problematic and was not conducted. Eight articles became available under an open access (OA) model at the time of publication, but today 66 more articles are available freely through different schemes. There seems to be no major difference in the number of OA 
TABLE 3 | The 20 terms that appeared most in the titles and abstracts of the 100 articles.

\begin{tabular}{|c|c|c|}
\hline Terms & Appearance & Citations per article \\
\hline Compound & 35 & 604 \\
\hline Medicinal plant & 32 & 640 \\
\hline Biological activity & 31 & 547 \\
\hline Use & 31 & 679 \\
\hline Extract & 29 & 658 \\
\hline Source & 26 & 663 \\
\hline Property & 22 & 567 \\
\hline System & 22 & 588 \\
\hline Number & 21 & 573 \\
\hline Medicine & 20 & 522 \\
\hline Species & 20 & 640 \\
\hline Traditional medicine & 19 & 520 \\
\hline Antioxidant activity & 17 & 797 \\
\hline Constituent & 18 & 558 \\
\hline Disease & 18 & 482 \\
\hline Drug & 18 & 622 \\
\hline Treatment & 17 & 596 \\
\hline Component & 16 & 588 \\
\hline Mechanism & 15 & 566 \\
\hline Antimicrobial activity & 13 & 596 \\
\hline
\end{tabular}

articles among the highly cited and the less cited (Top 100: 8 OA articles, Rank 1000-1100: 9 OA articles, Rank 1900-2000: 5 $\mathrm{OA}$ articles). This is in line with the findings from life science research that open access might be associated with more full text downloads without an actual citation advantage (Davis et al., 2008).

\section{What Can We Learn From the Highly Cited Papers in This Field in the Context of Ethnopharmacology's Wider and Changing Relevance Within the Natural Sciences?}

The 100 articles were binarized into pre-2000 (the year 2000 inclusive) and post-2000 publications and assessed. There were 32 pre-2000 and 68 post- 2000 publications. The topics of pre2000 publications appeared to be more focused, with only several specific plants or food appearing in multiple (i.e., two or more) articles, namely garlic, onion, propolis, rosemary, sage and Withania somnifera (L.) Dunal. Each appeared in two articles published pre-2000. The foci of post-2000 publications, on the other hand, seemed to be more diversified and involved more plants or food, namely aloe vera, cinnamon, clove, Coccinia grandis (L.) Voigt, C. longa L., Eucalyptus, ginger, Gymnema sylvestre (Retz.) R.Br. ex Sm., Momordica charantia L., mushroom, origanum, pomegranate, sage (Salvia officinalis L.), thyme and yeast. Except for C. longa, M. charantia and yeast that have had three appearances each, the other species and foods have appeared twice in the post-2000 publications. The post2000 publications have shifted foci compared to their pre-2000 counterparts, with the evidence that sage is the only plant that has appeared multiple times both in pre-2000 and post-2000 publications.

Another noticeable point is that post-2000 publications had evaluated wider aspects of effects of the medicinal plants and functional food. For instance, post-2000 publications focus more on antibacterial, anticancer, anticandidal, antifungal, antimicrobial, antioxidant, and antitumor activities, while pre2000 publications only referred to antibacterial, antimicrobial, and antioxidant activities.

\section{Who and What Has Driven the Research?}

The 100 most-cited articles were contributed by a total of 159 authors. Only one author, Bharat Bhushan Aggarwal, has contributed to four publications making him the only one to contribute three or more of the 100 most-cited articles. He authored four of them. All of them were published post-2000. No author has multiple contributions to the pre-2000 articles. The 100 articles were contributed by 160 affiliations. Those with three or more articles were University of Texas M. D. Anderson Cancer Center $(n=5)$, The University of Hong Kong $(n=3)$, and University of Illinois at Chicago $(n=3)$. All but one of these 11 articles were published post-2000. No affiliation has multiple contributions to the pre-2000 articles.

The 100 articles originated from 40 countries/territories, with the top contributions being by The United States $(n=29)$ and India $(n=13)$ (Table 4). Also noticeable countries/territories were China $(n=8)$, the United Kingdom $(n=8)$, Brazil $(n=5)$, and Germany $(n=5)$. In summary, the 100 articles had major contributions, not mutually exclusive, from countries/territories from Europe $(n=41)$, Asia $(n=39)$, and North America $(n=32)$, and some contributions from South America $(n=6)$, Africa $(n=6)$, and Oceania $(n=2)$. Comparing the articles published pre- and post-2000, The United States, India, and United Kingdom were listed among the top 5 contributors in both periods. However, China and Iran have a much larger contribution in the post-2000 publications (China: $n=7$, Iran: $n=4$ ) compared to the pre-2000 publications (China: $n=1$, Iran: $n=0$ ), and they have consequently replaced Brazil and Germany as members of the top five contributors.

Geography and culture have been an integral part of ethnopharmacology. Interestingly, only one of the 100 articles related to the social sciences aspects, which examined the use of medicinal plants in four indigenous groups of Mexican Indians (Heinrich et al., 1998). Perhaps in the future, more attention should be directed toward the cultural aspects of ethnopharmacology.

\section{Limitations}

The list of top 100 most cited articles, by its nature, has inherent limitations. The first and foremost limitation is the search strategy. An article would not be identified if its title, abstract, and keywords did not contain the pre-defined search terms. The second limitation is the definition of ethnopharmacology. For instance, one paper (Chatterjee et al., 1998) reported on the efficacy of the extract from a licensed European medicinal plant (St. John's wort) as antidepressant, and it surely deals with neuropharmacology, but it may or may not constitute 
TABLE 4 | Countries/territories contributed to the 100 most cited ethnopharmacology articles.

\begin{tabular}{|c|c|}
\hline Country/territory & Number of articles \\
\hline United States & 29 \\
\hline India & 13 \\
\hline China & 8 \\
\hline United Kingdom & 8 \\
\hline Brazil & 5 \\
\hline Germany & 5 \\
\hline Hong Kong SAR (China) & 4 \\
\hline Iran & 4 \\
\hline Israel & 4 \\
\hline Netherlands & 3 \\
\hline South Africa & 3 \\
\hline Spain & 3 \\
\hline Turkey & 3 \\
\hline Belgium & 2 \\
\hline Canada & 2 \\
\hline Japan & 2 \\
\hline Poland & 2 \\
\hline Singapore & 2 \\
\hline South Korea & 2 \\
\hline Ukraine & 2 \\
\hline
\end{tabular}

Countries/territories that each contributed to one article included Algeria, Argentina, Australia, Austria, Bulgaria, Croatia, Denmark, Finland, France, Italy, Lithuania, Mauritius, Mexico, New Zealand, Nigeria, Oman, Pakistan, Switzerland, Taiwan, and United Arab Emirates.

ethnopharmacology sensu stricto. Meanwhile, papers would be excluded from the current study if they were classed strictly as drug discovery or the title, abstracts or keywords assigned by EMTREE or MeSH did not contain the pre-defined key words related to ethnopharmacology. For example, some very widely used reviews on drug discovery from natural sources are not coded in such a way that they are included in this list: (Newman et al., 2003; Newman and Cragg, 2007) (These papers have 1,860 and 2,594 citations recorded by Scopus, respectively). This suggests a need for a top-level keyword (such as ethnopharmacology or traditional medicine) to be used widely. Ethnopharmacology or, more generally, the information which forms the basis of research and development activities, is still not well-recognized as an important element of the industrial development pipeline. This contradicts the common perception that ethnopharmacology is seen as an important source for new medicines. In essence, this also reflects the classical separation of the natural sciences into defined disciplines like chemistry and pharmacology, with ethnopharmacology being more strongly linked to pharmacology (and food science). Lastly, this work is based on a retrospective analysis and highlights research interests of the last decade or the last two decades and will be changing citation preferences in the future. It can be argued that the field may be shifting away from antioxidants and food science as some journals are now rejecting manuscripts based solely on in silico or simple antioxidant assays of food (Harnly,
2017). This also includes Frontiers in Pharmacology (section Ethnopharmacology) and the Journal of Ethnopharmacology. However, this latest shift has yet to be reflected in terms of citations.

\section{What Can We Learn From This for the Future Development of the Field?}

The research into bioactive natural products from medicinal plants has a long tradition, with many groups in the nineteenth century starting to search for the active principles in medicinal products and with an interest in the species pharmacology (Heinrich and Jäger, 2015). With the booming literature in neuroscience and nutritional neuroscience (Yeung et al., $2017 b$ ), it would not be surprising to see stronger links of ethnopharmacology to neuroscience, neuropharmacology and food science in the near future. This would also bring ethnopharmacology back to its "roots," since the early developments were driven by scientific interests in psychoactive plants (Heinrich, 2013). For instance, future research may shed light on how ingredients from medicinal plants would modulate, or even treat, eating or neuropsychiatric disorders. Such effects may be manifested as brain perfusion changes recorded by functional magnetic resonance imaging (Yeung et al., 2016, 2018). Metabolic syndrome and diabetes will continue to be a key area of interest and will strengthen the links into preventive medicine and food sciences. In future, this field should move away further from papers focused solely on in silico or on simple antioxidant screening reports to papers introducing new methods applicable to ethnopharmacology, which is largely missing from the current top 100 list.

\section{CONCLUSIONS}

We have identified the 100 most-cited articles in ethnopharmacology. This analysis identifies what has been seen to be of such importance in scientific terms that it is commonly used in citations. Some surprising outcomes include the important link to food sciences, and the relevance of some biological assays, which, in reality, are not considered to be of pharmacological relevance. Some other areas are notably absent including stronger links into neuropharmacology and a lack appreciation of social and cultural sciences approaches. The analysis demonstrated that ethnopharmacology is at the crossroads of several disciplines (most notably pharmacology and food science) and it is the ethnopharmacologists' challenge and opportunity to define this area in new ways, including the development of new links and foci (cf. Nina Etkin's work, e.g., Etkin and Ross, 1991). In a book published in 2015 a large number of contributors provided a short definition of what they consider ethnopharmacology to be Heinrich and Jäger (2015). The diversity of their responses with foci on pharmacology, clinical research, cultural sciences and studies, biological sciences and environmental research are reflected in the diversity seen in this bibliometric analysis. This diversity clearly is one of the key strengths, but also a challenge of ethnopharmacology, which sees itself to be inter- or trans-disciplinary. 


\section{AUTHOR CONTRIBUTIONS}

$\mathrm{AY}, \mathrm{MH}$, and AA: conceived the work; AY: acquired data and drafted the work; $\mathrm{AY}, \mathrm{MH}$, and AA: analyzed data; $\mathrm{MH}$ and $\mathrm{AA}$ : critically revised the work. All authors have approved the final content of the manuscript.

\section{REFERENCES}

Aggarwal, B. B., Sundaram, C., Malani, N., and Ichikawa, H. (2007). "Curcumin: the Indian solid gold," in The Molecular Targets and Therapeutic Uses of Curcumin in Health and Disease, eds B. B. Aggarwal, Y.-J. Surh, and S. Shishodia (Berlin: Springer), 1-75.

Atanasov, A. G., Waltenberger, B., Pferschy-Wenzig, E.-M., Linder, T., Wawrosch, C., Uhrin, P., et al. (2015). Discovery and resupply of pharmacologically active plant-derived natural products: a review. Biotechnol. Adv. 33, 1582-1614. doi: 10.1016/j.biotechadv.2015.08.001

Bailey, C. J., and Day, C. (1989). Traditional plant medicines as treatments for diabetes. Diabetes Care 12, 553-564. doi: 10.2337/diacare.12.8.553

Balunas, M. J., and Kinghorn, A. D. (2005). Drug discovery from medicinal plants. Life Sci. 78, 431-441. doi: 10.1016/j.lfs.2005.09.012

Bisogno, T., Hanuš, L., De Petrocellis, L., Tchilibon, S., Ponde, D. E., Brandi, I., et al. (2001). Molecular targets for cannabidiol and its synthetic analogues: effect on vanilloid VR1 receptors and on the cellular uptake and enzymatic hydrolysis of anandamide. Br. J. Pharmacol. 134, 845-852. doi: 10.1038/sj.bjp.0704327

Block, E. (1992). The organosulfur chemistry of the genus Allium-implications for the organic chemistry of sulfur. Angew. Chem. Int. Ed. 31, 1135-1178. doi: 10.1002/anie.199211351

Booker, A., Johnston, D., and Heinrich, M. (2012). Value chains of herbal medicines-Research needs and key challenges in the context of ethnopharmacology. J. Ethnopharmacol. 140, 624-633. doi: 10.1016/j.jep.2012.01.039

Chatterjee, S., Bhattacharya, S., Wonnemann, M., Singer, A., and Müller, W. (1998). Hyperforin as a possible antidepressant component of hypericum extracts. Life Sci. 63, 499-510. doi: 10.1016/S0024-3205(98)00299-9

Cragg, G. M., and Newman, D. J. (2005). Plants as a source of anti-cancer agents. J. Ethnopharmacol. 100, 72-79. doi: 10.1016/j.jep.2005.05.011

Cragg, G. M., and Newman, D. J. (2013). Natural products: a continuing source of novel drug leads. Biochim. Biophys. Acta 1830, 3670-3695. doi: 10.1016/ j.bbagen.2013.02.008

Davis, P. M., Lewenstein, B. V., Simon, D. H., Booth, J. G., and Connolly, M. J. (2008). Open access publishing, article downloads, and citations: randomised controlled trial. BMJ 337:a568. doi: 10.1136/bmj.a568

Diplock, A., Charuleux, J.-L., Crozier-Willi, G., Kok, F., Rice-Evans, C., Roberfroid, M., et al. (1998). Functional food science and defence against reactive oxidative species. Br. J. Nutr. 80, S77-S112. doi: 10.1079/BJN19980106

Eisenberg, D. M., Davis, R. B., Ettner, S. L., Appel, S., Wilkey, S., Van Rompay, M., et al. (1998). Trends in alternative medicine use in the United States, 1990-1997: results of a follow-up national survey. JAMA 280, 1569-1575. doi: 10.1001/jama.280.18.1569

Etkin, N. L., and Ross, P. J. (1991). Should we set a place for diet in ethnopharmacology? J. Ethnopharmacol. 32, 25-36. doi: 10.1016/0378-8741(91)90100-R

Fabricant, D. S., and Farnsworth, N. R. (2001). The value of plants used in traditional medicine for drug discovery. Environ. Health Perspect. 109, 69-75. doi: 10.1289/ehp.01109s169

Gilani, A. H. (2005). Trends in ethnopharmacology. J. Ethnopharmacol. 100, 43-49. doi: 10.1016/j.jep.2005.06.001

Gorraiz, J., and Schloegl, C. (2008). A bibliometric analysis of pharmacology and pharmacy journals: scopus versus web of science. J. Inf. Sci. 34, 715-725. doi: 10.1177/0165551507086991

Gurib-Fakim, A. (2006). Medicinal plants: traditions of yesterday and drugs of tomorrow. Mol. Aspects Med. 27, 1-93. doi: 10.1016/j.mam.2005.07.008

\section{FUNDING}

AA acknowledges the support by the Polish KNOW (Leading National Research Centre) Scientific Consortium Healthy Animal-Safe Food, decision of Ministry of Science and Higher Education No. 05-1/KNOW2/2015.

Harnly, J. (2017). Antioxidant methods. J. Food Compos. Anal. 64, 145-146. doi: 10.1016/j.jfca.2017.08.011

Harvey, A. L. (2008). Natural products in drug discovery. Drug Discov. Today 13, 894-901. doi: 10.1016/j.drudis.2008.07.004

Heersmink, R., Van Den Hoven, J., Van Eck, N. J., and Van Den Berg, J. (2011). Bibliometric mapping of computer and information ethics. Ethics Inf. Technol. 13, 241-249. doi: 10.1007/s10676-011-9273-7

Heinrich, M. (2000). Ethnobotany and its role in drug development. Phytother. Res. 14, 479-488. doi: 10.1002/1099-1573(200011)14:7<479::AID-PTR958>3.0. $\mathrm{CO} ; 2-2$

Heinrich, M. (2013). "Ethnopharmacology and drug discovery," in Elsevier Reference Module in Chemistry, Molecular Sciences and Chemical Engineering, ed J. Reedijk (Waltham, MA: Elsevier), 351-377.

Heinrich, M., Ankli, A., Frei, B., Weimann, C., and Sticher, O. (1998). Medicinal plants in Mexico: healers' consensus and cultural importance. Soc. Sci. Med. 47, 1859-1871. doi: 10.1016/S0277-9536(98)00181-6

Heinrich, M., and Jäger, A. K. (2015). Ethnopharmacology. Chichester: John Wiley \& Sons.

Heinrich, M., Lardos, A., Leonti, M., Weckerle, C., Willcox, M., with the ConSEFS Advisory Group, et al. (2018). Best practice in research: consensus statement on ethnopharmacological field studies-ConSEFS. J. Ethnopharmacol. 211, 329-339. doi: 10.1016/j.jep.2017.08.015

Kedare, S. B., and Singh, R. (2011). Genesis and development of DPPH method of antioxidant assay. J. Food Sci. Technol. 48, 412-422. doi: 10.1007/s13197-011-0251-1

Kim, H. J., Yoon, D. Y., Kim, E. S., Lee, K., Bae, J. S., and Lee, J.-H. (2016). The 100 most-cited articles in neuroimaging: a bibliometric analysis. Neuroimage 139, 149-156. doi: 10.1016/j.neuroimage.2016.06.029

Klayman, D. L. (1985). Qinghaosu (artemisinin): an antimalarial drug from China. Science 228, 1049-1056. doi: 10.1126/science.3887571

Kronenberg, F., and Fugh-Berman, A. (2002). Complementary and alternative medicine for menopausal symptoms: a review of randomized, controlled trials. Ann. Intern. Med. 137, 805-813. doi: 10.7326/0003-4819-13710-200211190-00009

Kumar, S., and Pandey, A. K. (2013). Chemistry and biological activities of flavonoids: an overview. Sci. World J. 2013:162750. doi: 10.1155/2013/162750

Menrad, K. (2003). Market and marketing of functional food in Europe. J. Food Eng. 56, 181-188. doi: 10.1016/S0260-8774(02)00247-9

Newman, D. J., and Cragg, G. M. (2007). Natural products as sources of new drugs over the last 25 years. J. Nat. Prod. 70, 461-477. doi: 10.1021/np068054v

Newman, D. J., Cragg, G. M., and Snader, K. M. (2003). Natural products as sources of new drugs over the period 1981-2002. J. Nat. Prod. 66, 1022-1037. doi: 10.1021/np0300961

Roth, B. L., Baner, K., Westkaemper, R., Siebert, D., Rice, K. C., Steinberg, S., et al. (2002). Salvinorin A: a potent naturally occurring nonnitrogenous к opioid selective agonist. Proc. Natl. Acad. Sci. U.S.A. 99, 11934-11939. doi: 10.1073/pnas.182234399

Rozema, E., Atanasov, A., Fakhrudin, N., Singhuber, J., Namduang, U., Heiss, E., et al. (2012). Selected extracts of Chinese herbal medicines: their effect on NF$\kappa \mathrm{B}, \mathrm{PPAR} \alpha$ and PPAR $\gamma$ and the respective bioactive compounds. Evid. Based Complement. Altern. Med. 2012:983023. doi: 10.1155/2012/983023

Sheng-Ji, P. (2001). Ethnobotanical approaches of traditional medicine studies: some experiences from Asia. Pharm. Biol. 39, 74-79. doi: 10.1076/phbi. 39.s1.74.0005

Singh, S. (2007). From exotic spice to modern drug? Cell 130, 765-768. doi: $10.1016 /$ j.cell.2007.08.024 
Smit, A. J. (2004). Medicinal and pharmaceutical uses of seaweed natural products: a review. J. Appl. Phycol. 16, 245-262. doi: 10.1023/B:JAPH. 0000047783.36600.ef

Steenkamp, V., Mathivha, E., Gouws, M., and Van Rensburg, C. (2004). Studies on antibacterial, antioxidant and fibroblast growth stimulation of wound healing remedies from South Africa. J. Ethnopharmacol. 95, 353-357. doi: 10.1016/j.jep.2004.08.020

Tran, T. V. A., Malainer, C., Schwaiger, S., Hung, T., Atanasov, A. G., Heiss, E. H., et al. (2015). Screening of Vietnamese medicinal plants for NF- $\kappa B$ signaling inhibitors: assessing the activity of flavonoids from the stem bark of Oroxylum indicum. J. Ethnopharmacol. 159, 36-42. doi: 10.1016/j.jep.2014. 10.012

Tsai, Y.-L., Lee, C.-C., Chen, S.-C., and Yen, Z.-S. (2006). Top-cited articles in emergency medicine. Am. J. Emerg. Med. 24, 647-654. doi: 10.1016/j.ajem.2006.01.001

Van Eck, N. J., and Waltman, L. (2009). Software survey: VOSviewer, a computer program for bibliometric mapping. Scientometrics 84, 523-538. doi: 10.1007/s11192-009-0146-3

Vicentini, A., Liberatore, L., and Mastrocola, D. (2016). Functional foods: trends and development of the global market. Ital. J. Food Sci. 28, 338-351. doi: $10.14674 / 1120-1770 /$ ijfs.v211

Vickery, B. C. (1948). Bradford's law of scattering. J. Doc. 4, 198-203. doi: $10.1108 /$ eb026133

Vimala, S., Norhanom, A., and Yadav, M. (1999). Anti-tumour promoter activity in Malaysian ginger rhizobia used in traditional medicine. Br. J. Cancer 80, 110-116. doi: 10.1038/sj.bjc. 6690329

Vogl, S., Picker, P., Mihaly-Bison, J., Fakhrudin, N., Atanasov, A. G., Heiss, E. H., et al. (2013). Ethnopharmacological in vitro studies on Austria's folk medicine-An unexplored lore in vitro anti-inflammatory activities of 71 Austrian traditional herbal drugs. J. Ethnopharmacol. 149, 750-771. doi: 10.1016/j.jep.2013.06.007

Yeung, A. W. K., Goto, T. K., and Leung, W. K. (2017a). At the leading front of neuroscience: a bibliometric study of the 100 most-cited articles. Front. Hum. Neurosci. 11:363. doi: 10.3389/fnhum.2017.00363

Yeung, A. W. K., Goto, T. K., and Leung, W. K. (2017b). A bibliometric review of research trends in neuroimaging. Curr. Sci. 112, 725-734. doi: $10.18520 / \mathrm{cs} / \mathrm{v} 112 / \mathrm{i} 04 / 725-734$

Yeung, A. W. K., Goto, T. K., and Leung, W. K. (2017c). The changing landscape of neuroscience research, 2006-2015: a bibliometric study. Front. Neurosci. 11:120. doi: 10.3389/fnins.2017.00120

Yeung, A. W. K., Goto, T. K., and Leung, W. K. (2018). Affective value, intensity and quality of liquid tastants/food discernment in the human brain an activation likelihood estimation meta-analysis. Neuroimage 169, 189-199. doi: 10.1016/j.neuroimage.2017.12.034

Yeung, A. W. K., Tanabe, H. C., Suen, J. L. K., and Goto, T. K. (2016). Taste intensity modulates effective connectivity from the insular cortex to the thalamus in humans. Neuroimage 135, 214-222. doi: 10.1016/j.neuroimage.2016.04.057

Conflict of Interest Statement: The authors declare that the research was conducted in the absence of any commercial or financial relationships that could be construed as a potential conflict of interest.

Copyright $\odot 2018$ Yeung, Heinrich and Atanasov. This is an open-access article distributed under the terms of the Creative Commons Attribution License (CC $B Y)$. The use, distribution or reproduction in other forums is permitted, provided the original author(s) and the copyright owner are credited and that the original publication in this journal is cited, in accordance with accepted academic practice. No use, distribution or reproduction is permitted which does not comply with these terms. 